\title{
Detecção do Chafariz Histórico de Santa Rita através do GPR
}

\author{
${ }^{1}$ João Carlos Nara Júnior; ${ }^{2}$ Gleide Alencar do Nascimento Dias $;{ }^{3}$ Willian Cruz Gouvea Junior \\ ${ }^{1}$ Universidade Federal do Rio de Janeiro, Instituto de História, Programa de Pós-graduação em História Comparada. ${ }^{2,3}$ Universidade \\ Federal do Rio de Janeiro, Instituto de Geociências, Departamento de Geologia, Laboratório de Física
}

\section{Copyright 2016, SBGf - Sociedade Brasileira de Geofísica}

Este texto foi preparado para a apresentação no VII Simpósio Brasileiro de Geofísica, Ouro Preto, 25 a 27 de outubro de 2016. Seu conteúdo foi revisado pelo Comitê Técnico do VII SimBGf,mas não necessariamente representa a opinião da SBGf ou de seus associados. É proibida a reprodução total ou parcial deste material para propósitos comerciais sem prévia autorização da SBGf.

\section{Resumo}

Este trabalho centra-se em analisar vestígios históricos do Largo de Santa Rita de Cássia, no Centro do Rio de Janeiro, o qual passou por inúmeras transformações. Durante o período colonial albergou um cemitério de pretos novos, isto é, exclusivo para os cativos que morreram antes de ser vendidos. Posteriormente, já nó século XIX, para higienizar a cidade das epidemias mortíferas que a assolavam, o Largo foi contemplado com um chafariz. Em 1884 o chafariz foi substituído por uma fonte de ferro, o qual desapareceria vinte anos depois em virtude das reformas urbanas do prefeito Pereira Passos. Atualmente, o Largo de Santa Rita encontra-se reduzido e, acredita-se onde havia o chafariz, haja uma banca de jornal. As seções radargramas foram direcionadas de acordo com a literatura arqueológica e histórica conhecida para a área. Este trabalho consistiu em verificar a aplicabilidade do método GPR (Ground Penetrating Radar) na localização de tubulações de ferro fundido utilizados para o escoamento de águas pluviais e de esgoto daquelas épocas até mesmo a fim de localizar o chafariz. A fim de alcançar este objetivo foram adquiridos 17 perfis dentro da área de estudo, utilizando-se uma antena de 200 $\mathrm{MHz}$, todas adquiridas em paralelo. Após o processamento dos dados e a análise de todos os radargramas, em geral, apresentou alguns bons resultados podendo ser identificada quase todas as tubulações subsuperficiais de ferro e de concreto através da presença de feições hiperbólicas, formadas pela difração das ondas eletromagnéticas nestes materiais. Somente em alguns perfis não foi possível identificar alguns desses dutos, devido a presença de um forte ruído causado pela reverberação do sinal nas antenas (ringing). Foi possível verificar 7 tubulações em maior destaque nas seções radargramas. Após o estudo, podemos concluir que o método GPR é muito útil na localização de tubulações, podendo ser extrapolado para outras áreas onde não se detém nenhum conhecimento prévio da subsuperfície. A presença do chafariz não foi identificada diretamente na área em estudo mas foram encontradas as direções das tubulações que podem indicar a direção da origem do chafariz

\section{Introdução}

Geofísica é o estudo da Terra por métodos físicos (Magnetometria, Resistividade Elétrica, Condutividade, Susceptibilidade Magnética, Radar de Penetração no Solo - GPR e etc), que são utilizados para detectar, mapear e caracterizar fenômenos subsuperficiais incluindo depósitos arqueológicos enterrados. Uma utilização eficaz da geofísica pode melhorar a confiabilidade, reduz a capacidade de invasão e, em muitos casos, reduzir os custos globais de investigações arqueológicas (Hargrave, 2002 Apud Ernenwein and Hargrave, 2009). A profundidade investigada nos contextos arqueológicos refere-se de 1 a $2 \mathrm{~m}$ de profundidade. Ambos os métodos ativos e passivos são empregados no estudo.

Os dados de Radar de Penetração no Solo (GPR) são adquiridos por movimento do equipamento na área de estudo, na maioria das vezes em movimentos uniformemente espaçados e paralelos. Estas medições são normalmente em formato $x y z$ (onde $x$, y dão as coordenadas de localização e $z$ é a geofísica de medição) são então compilados em um banco de dados e exibidos para criar mapas de contorno ou imagens que retratam a variação espacial nas propriedades medidas.

O primeiro levantamento geofísico sistemática em um sítio arqueológico nos EUA foi realizado em Williamsburg, VA, em 1938. Usando método geofísico equipotencial. Outra aplicação que foi um marco da geofísica ocorreu em 1958, quando Martin Aitken utilizando um magnetômetro de prótons detectou um forno perto Peterborough, Reino Unido (Gaffney and Gater 2003, Apud Ernenwein and Hargrave, 2009). Durante os anos de 1970, a geofísica começou a ser integrada a arqueologia na Grã-Bretanha e em partes da Europa. Sítios pré-históricos romanos nessas áreas muitas vezes incluem artefatos de metal, pedra e arquitetura de alvenaria e telhas de barro. Tais materiais contrastam fortemente com os seus arredores e poderiam ser 
identificados em mapas que foram caracterizados por relativamente poucos de dados, amplamente espaçados.

O GPR foi adicionado um pouco mais tarde aos métodos geofísicos. Esse foi inicialmente desenvolvido para localizar cavidades subsuperficiais, tais como minas e túneis. Ele foi rapidamente adotado pela geologia, engenharia civil, e muitas outras disciplinas. Em 1975, uma das primeiras aplicações arqueológicos de GPR foi um para mapear paredes enterradas em Chaco Canyon, NM (Vickers, et al., 1976 Apud Ernenwein and Hargrave, 2009). Outras pesquisas nos EUA com GPR foram focadas em elementos históricos, tais como adegas e paredes de pedra enterradas. Utilização de GPR nos Estados Unidos continuou durante os anos 1980 e 1990, demonstrando o potencial da técnica para a detecção de uma ampla variedade de tipos de recursos.

\section{Metodologia}

O GPR é um método geofísico não destrutivo e não invasivo, que produz perfis contínuos, com ou sem a possibilidade de aquisição de um grande volume de dados em um curto período de tempo (Knight, 2001). Este método eletromagnético emprega ondas de rádio em altas frequências (10-2500 MHz), que são emitidas para a subsuperfície através de uma antena (transmissora) em superfície, propagando para o interior do solo refletindo-se e/ou difratando-se nas feições de subsuperfície em meio contrastante de permissividade dielétrica. $\mathrm{E}$ retornando a superfície, sendo registrada numa antena (receptora).As antenas de GPR podem ser usadas dentro de um poço e em superfície, onde os dados são adquiridos de modo rápido o que se permite investigar grandes áreas (Dias, 2007).

\section{História do chafariz de Santa Rita}

Muitos pesquisadores do Rio de Janeiro têm se debruçado sobre a Freguesia de Santa Rita de Cássia, cujo templo, construído entre 1702 e 1751, constitui a primeira aparição do rococó religioso na América e é o único remanescente na cidade do Rio de Janeiro cuja talha ornamental não sofreu acréscimos posteriores.

Ao longo de seus mais de 300 anos de existência, - Largo de Santa Rita de Cássia, no Centro do Rio de Janeiro, passou por inúmeras transformações (cf. o detalhe do Mapa Arquitetural do século XIX na Figura 1). Durante o período colonial albergou um cemitério de pretos novos, isto é, exclusivo para os cativos que morreram antes de ser vendidos. Posteriormente, já nó século XIX, para higienizar a cidade das epidemias mortíferas que a assolavam, o Largo foi contemplado com um chafariz. Em 1884 o chafariz foi substituído por uma fonte de ferro, o qual desapareceria vinte anos depois em virtude das reformas urbanas do prefeito Pereira Passos (Figura 2). Atualmente, o Largo de Santa Rita encontra-se reduzido e, onde havia o chafariz, apenas há uma banca de jornal.
A antiga fonte, cujas águas provinham da Carioca, aparece no famoso quadro de Eduard Hildebrandt (Figura 3), datado de 1844. Ela era octogonal, composta de quatro corpos sobrepostos, e possuía em seus ângulos externos fradinhos com mastro e lampiões de azeite. Com relação ao abastecimento, Francisco Ramiro de Assis Coelho, ministro do Império, relatava à Assembleia Legislativa que:

"Encomendou o governo para a Inglaterra um encanamento de chumbo da extensão de 3.290 pés ingleses (aproximadamente $1002 \mathrm{~m}$ ) pondo à disposição do nosso Encarregado de Negócios, em Londres, a quantia de 8:000\$000 para aquela despesa" (Relatório apresentado à Assembleia Geral Legislativa na seção ordinária de 1840, p. 60).

A localização dessas fontes reveste-se de grande interesse arqueológico para o resgate da cultura material do período escravagista carioca.

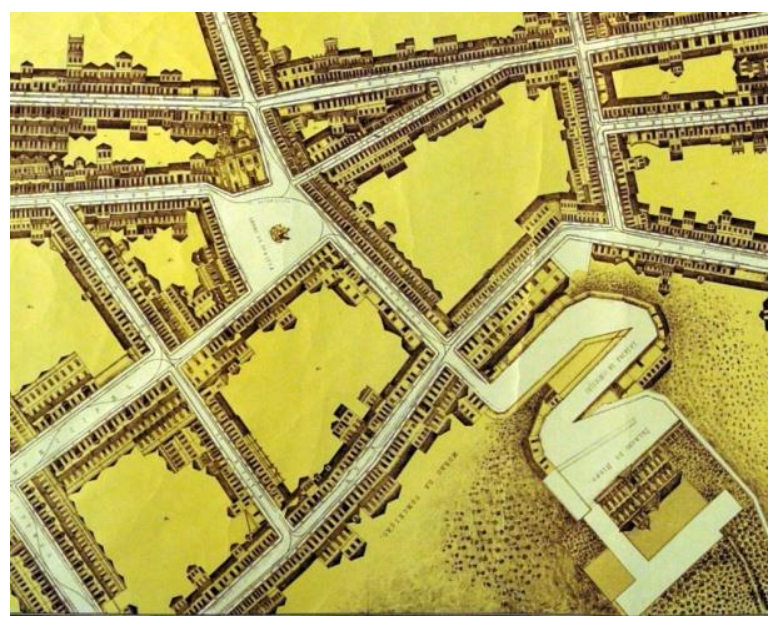

Figura 1 - Detalhe do Mapa Arquitetural da Cidade do Rio de Janeiro, 1874 (Bibliotheca Nacional). Vê-se o Largo de Santa Rita e a rua do Ourives (atual Rua Miguel Couto) que vai até a ladeira do então Palácio episcopal (atual Rua Major Daemon) 


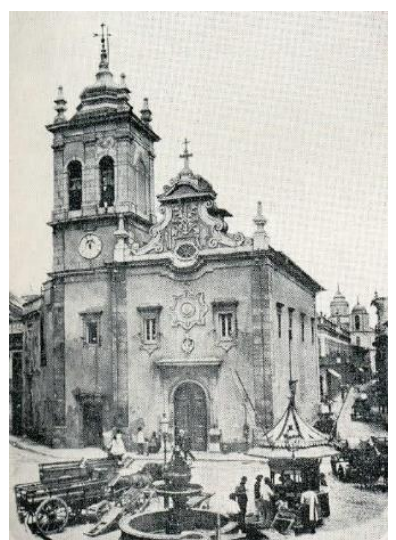

Figura 2 - $\mathrm{O}$ esguicho de ferro que substituiu a antiga fonte (1908).

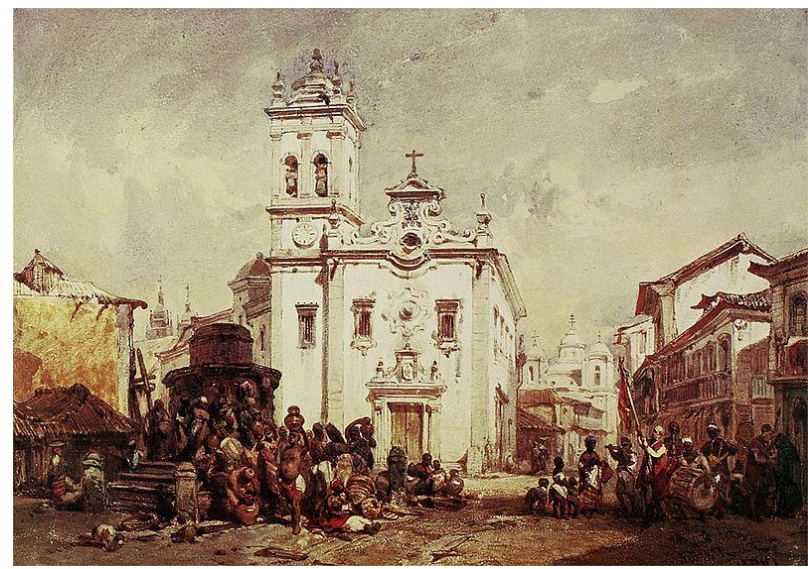

Figura 3 - Eduard Hildebrandt, Santa Rita, 1844. Distinguem-se à esquerda as torres da Candelária, e à direita as de São Pedro dos Clérigos, que foi demolida em meados do século XX.

O local de estudo hoje está compreendido nessa área, possui uma área de aproximadamente $600 \mathrm{~m}^{2}$, sendo um dos acessos feito pela Rua Visconde de Inhaúma perpendicular à Av. Presidente Vargas em $43^{\circ} 10^{\prime} 51.77^{\prime \prime} \mathrm{O}$ e $22^{\circ} 54^{\prime} 0.12^{\prime \prime S}$ (Figura 4). Na Figura 5 é possível verificar que na área de estudo possui uma banca de jornal e que essa se localização quase em frente a Igreja Santa Rita, vale ressaltar que a perspectiva de visão das Figuras 2, 3 e 5 podem indicar diferentes posições para a localização da presença do chafariz.

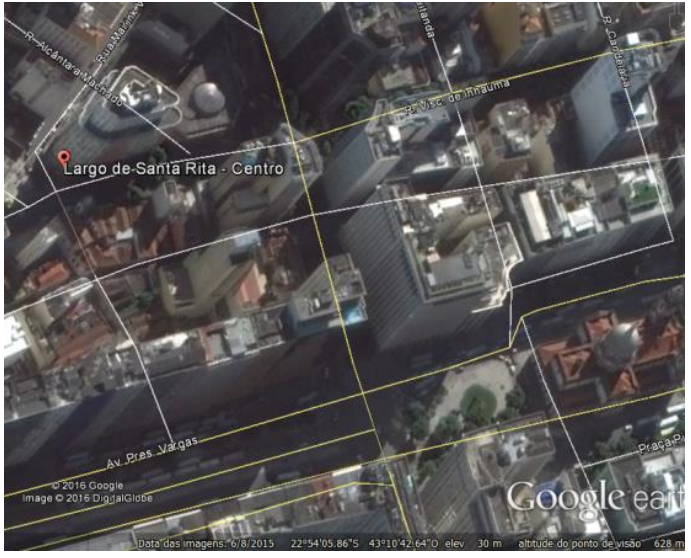

Figura 4 - Via de acesso ao Largo de Santa Rita (Google Earth, 2010).

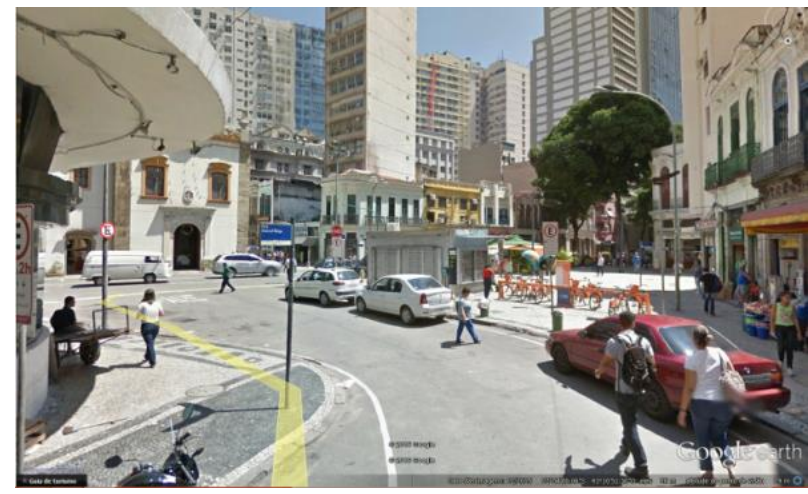

Figura 5 - Localização da área de estudo (Google Earth, 2010).

\section{Aquisição de Dados}

Há números sistemas de GPR desenvolvidos no mercado mundial. As três maiores empresas fornecedoras do equipamento são: Geophysical Survey Systems Incorporated (GSSI) (Norte-Americana), Senso sand Softwares (Canadense) e Mala Geosciences (Sueca). Estas empresas produzem vários modelos de sistemas de radar que podem operar em diversas faixas de frequências. Um sistema de radar consiste basicamente de quatro partes: um gerador de sinal (unidade transmissora), a unidade receptora, a unidade de controle digital e a unidade de visualização (display) (Figura 6). Para este trabalho foram realizados 17 perfis com um equipamento do modelo TerraSIRch SIR (Subsurface Interface Radar) System-3000 fabricado pela Geophysical Survey Systems, Inc. (GSSI), com antena blindada monoestática de $200 \mathrm{MHz}$. 


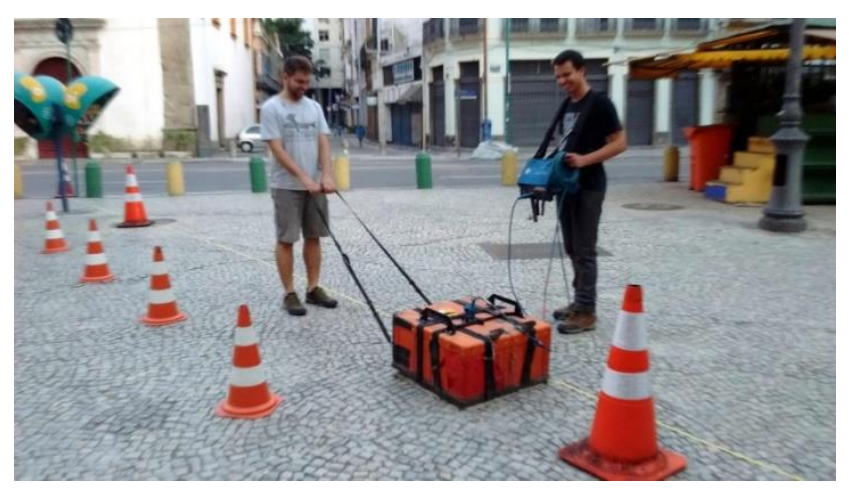

Figura 6 - Equipamento TerraSIRch SIR System-3000.

Muitos levantamentos geofísicos contemporâneos são feitas com um intervalo de amostragem de 0,5 - 0,125 por metro, com linhas espaçadas de 1 a $0,5 \mathrm{~m}$ de distância. Resolução de contraste com características, menores e inferiores, é melhorada através do aumento da densidade de dados. Ernenwein and Hargrave (2009) mostra que, como o intervalo de amostragem é diminuída $1,5-0,125 \mathrm{~m}$, a capacidade para diferenciar um forno a partir de um pedaço de ferro na superfície é aumentada (usando um magnetômetro). A experiência mostra que 0,5 $\mathrm{m}$ é o maior intervalo de tempo adequado, e há uma melhoria considerável em $0,25 \mathrm{~m}$, mas apenas melhorias marginais a $0,125 \mathrm{~m}$. Usando um intervalo de amostragem $0,25 \mathrm{~m}$ ou menor. O espaçamento selecionado para esse estudo foi de $10 \mathrm{~cm}$ entre os offsets, pois se poderia encontrar outros artefatos além das tubulações e entre as linhas 01 a 14 houve uma separação entre elas de $60 \mathrm{~cm}$ e a partir da 14 a 16 o espaçamento foi de $1,20 \mathrm{~m}$ e entre as linhas 16 e 17 o espaçamento foi de $7,20 \mathrm{~m} \mathrm{O}$ espaçamento em nosso estudo é considerado o fator mais importante devido a percepção do tamanho dos alvos a serem procurados na deteç̧ão e reconhecimento de características culturais.

\section{Processamento e Interpretação dos dados}

Após serem realizadas as aquisições dos dados, esses foram processados no software REFLEXW, versão 4.2 da empresa Sandmeier, seguiu-se as seguintes etapas no processamento a partir do dado bruto para filtrar ruídose realçar objetos de estudo relevantes:a) StaticCorrection/muting> Move StartTime. b) 1D-filter $>$ Subtract-mean (dewow). c) 2D-filter > Background Removal. d) 1D-filter >Bandpassfrequency. 2D-filter > Background Removal. e) Gain>Div. Compensation. F)Tracelnterpolation/Resorting $>$ XflipProfile

Apesar de terem sido obtidas 17 seções radargramas nesse estudo, aqui está sendo apresentado somente duas seções radargramas que apresentam mais significativos respostas,foi verificado neste perfil diferentes tubulações com variados diâmetros e de propriedades físicas
Nas linhas processadas não foi necessária a realização da correção topográfica, devido à baixa inclinação do terreno. Na interpretação utilizou-se a opção de interpolação do programa, a velocidade de aquisição dos dados foi constante. Para melhorar a visualização foi utilizado um ganho de visualização. Atenção especial foi aplicado para identificar a presença de hipérboles de tubulações presentes. Nos perfis são verificados em torno de $3 \mathrm{~m}$ a presença de refletores com inclinação de $45^{\circ}$ que são associados a reflexão das ondas eletromagnéticas no ar o qual houve a reflexão com as paredes das construções no início do perfil onde se começaram a serem realizadas as medidas, a blindagem da antena não forneceu um resultado eficiente, sendo presente. A migração não foi aplicada nos dados uma vez que foi usado a forma da hipérbole para verificar as tubulações, e a mesma poderia distorcer os dados

A pesquisa tem por objetivo verificar vestígios da arquitetura do chafariz. A interpretação dos dados foi baseada em radargramas 2D, para obter a melhor informação possível sobre as diferentes questões abordadas pela pesquisa GPR. A apresentação dos resultados e discussão irá abordar cada um destes objetivos individualmente. As setas em azul são verificadas nas seções da radargramas 4 a 12 do lado esquerdo do seção em profundidade próxima a superfície, as setas em preto também do lado esquerdo da seção apresentam-se nas seções radargramas 4 a $12 \mathrm{em}$ profundidade também próxima a superfície, as setas em amarelo do lado esquerdo das seções apresentam-se nas seções radargramas de 6 a 12, as setas em vermelho em profundidade de aproximadamente $2 \mathrm{~m}$ com afastamento do ponto zero do eixo $\mathrm{x}$ de $7 \mathrm{~m}$ indicam a presença de uma tubulação que possui certa inclinação e de ferro caracterizada pelo efeito (ringing). Em destaque do lado direito das seções radargramas são observadas 3 feições através de um círculo pontilhado em branco presente nas seções radargramas $5,6,8,9$ e 10, pode ser observado que essas apresentam fraco contraste com o meio sendo caracteriza de duas tubulações menores mais antigas e a central com maior tubulação com material diferente do ferro. Nas seções radargramas o contato do aterro mais recente com alterado de 1800 destacasse por feições estruturais mais variadas acima da linha branca e abaixo da linha branca apresença de reflexões mais plano paralelas, sendo um indicativo de solo mais antigo (Figura 7 e 8).

O ajuste hiperbólico produzido estimativa velocidade variando de 0,03 a 0,2 m/ns, revelando, assim, a heterogeneidade do solo, o que tornou a migração de dados difícil. 

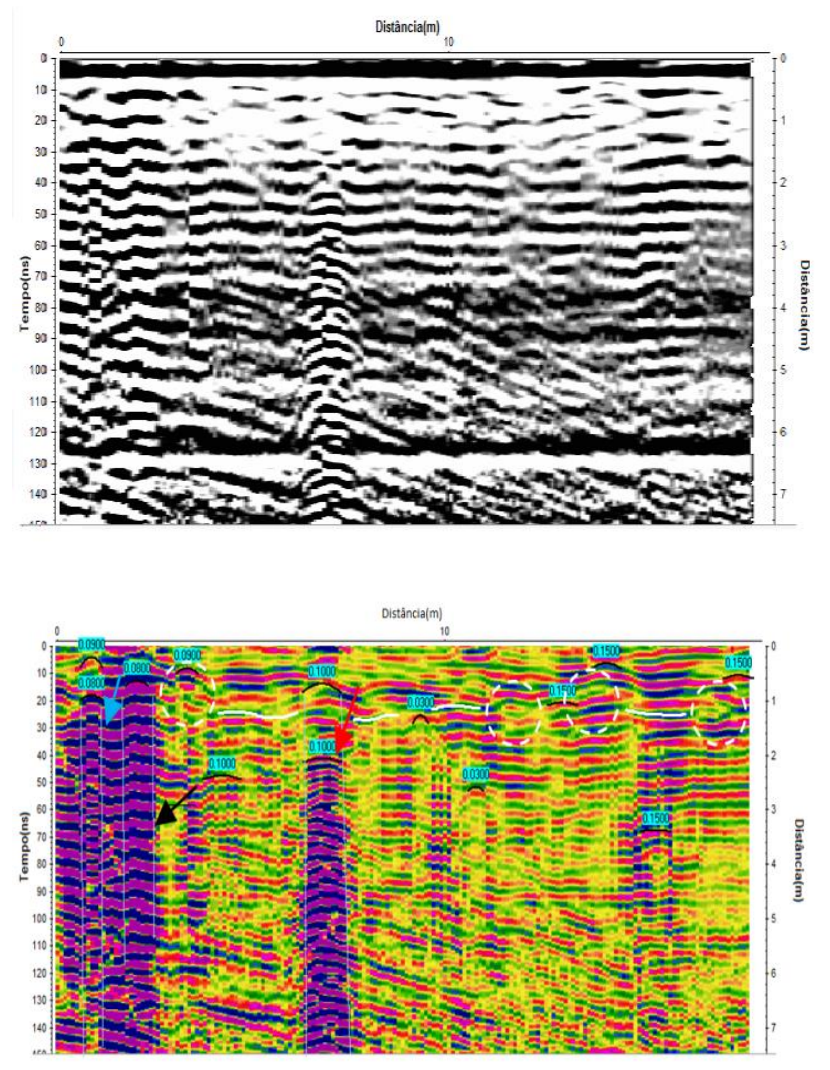

Figura 7 - Seção radargrama sem processamento acima e seção radargrama processada abaixo da linha 05 .

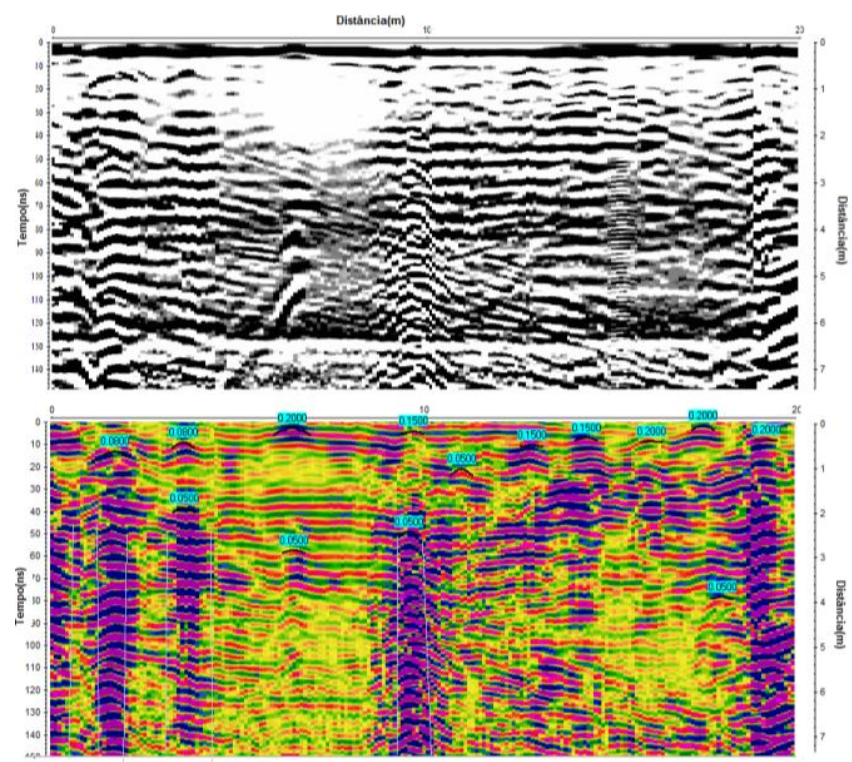

Figura 8 - Seção radargrama sem processamento acima e seção radargrama processada abaixo da linha 10.

\section{Conclusões}

A análise de todos os radargramas em geral apresentou bons resultados, e com isso pode-se concluir que o GPR é um método eficaz na detecção de contrastes bruscos.

Dentre as seções obtidas as que apresentaram mais resultados foram as linhas 05 e 10. As tubulações verificadas na parte esquerda, central e direita das seções radargramas representa novas e antigas tubulações que estão sendo utilizadas e que foram abandonadas, provavelmente de ferro fundido também. As feições abaixo das tubulações com efeito ringing não apresentaram boa nitidez, devido à presença de um forte ruído causado pela reverberação do sinal nas antenas. Em geral através das seções radargramas pode-se detectar as tubulações em estudo verificando-se a direção, profundidade e continuidade das tubulações em 3D.

É importante na etapa de interpretação das seções a experiência e conhecimento do intérprete, como também o conhecimento de informações prévias sobre o local de estudo que identifica estruturas arqueológicas em comparação mental, com anomalias reconhecidas e estruturas conhecidas da foto. Espera-se que a integração combinada de evidências de geofísica, sondagens, escavações, arquivos históricos e fotografias históricas e aéreas irão fornecer uma compreensão mais completa dos artefatos arqueológicos de Santa Rita que seria possível de uma escavação sozinha. Para sítios arqueológicos, é importante obter o máximo de informação possível, a fim de fornecer uma interpretação e, a fim de planejar escavações posteriores.

\section{Agradecimentos}

Ao Laboratório de Física do Departamento de Geologia da UFRJ.

\section{Referências}

Cart175745 - Fragoso, João da Rocha. Mappa architectural da cidade do Rio de Janeiro [Cartográfico]: Parte comercial. Rio de Janeiro: Genaro e Guilherme Rodrigues, 1971. 1 planta em 4 seções, $142 \times 122 \mathrm{~cm}$, cada seção $71 \times 61 \mathrm{~cm}+1$ folheto (19p.). Disponível em: <http://objdigital.bn.br/objdigital2/acervo_digital/div_cartogr afia/cart175745/cart175745.html>. Acesso em: 10 maio de 2016.

Dias G. A. N. 2007. Modelagem e Imageamento dos Dados de GPR Adquiridos em Afloramentos Visando o Estudo de Reservatório Petrolífero. Tese de Doutorado. Instituto de Geociências / UFRJ 
Ernenewin E.G. and Hargrave M. L. 2009. Archaeological Geophysics for Do Field Use: A Guide for New and Novice Users. ESTCP Project SI-0611.

Google Earth (2010).

Nara Jr., João Carlos. 2016. Arqueologia da persuasão: o simbolismo rococó da matriz de Santa Rita. Curitiba: Appris [no prelo]. 